\title{
Persecution-Induced Reduction in Earning Capacity of Holocaust Victims: Influence of Psychiatric and Somatic Aspects
}

\author{
Helge Müller Frank Seifert Rita Asemann Patricia Schütz Juan-Manuel Maler \\ Wolfgang Sperling
}

Department of Psychiatry and Psychotherapy, University of Erlangen-Nuremberg, Erlangen, Germany

\section{Key Words}

Persecution-induced reduction in earning capacity •

Primary and subsequent damage $\cdot$ Persecution-induced mental complaints - Holocaust posttraumatic syndrome • Posttraumatic stress disorder

\begin{abstract}
The incidence of mental and somatic sequelae is very high in the group of persons damaged by the Holocaust. Based on the sociomedical criteria prevailing in Germany, the assessment of persecution-induced reduction in earning capacity of Holocaust victims (vMdE) is mainly orientated towards direct Holocaust-induced somatic and mental sequelae but must also take into account the interaction of direct Holocaust-induced damage with subsequently acquired physical, mental, and psychosocial factors. The current medical evaluation is focused on the question whether persecution-induced symptoms are exacerbated by endogenous factors like mental or somatic diseases and/or exogenous factors like life events. In that case the grade of vMdE could be increased. Based on the synopsis of 56 Holocaust victims, we ascertained in this study that newly acquired somatic diseases and psychic morbidities contribute to an increase in persecution-induced mental complaints.
\end{abstract}

Copyright $\odot 2011$ S. Karger AG, Basel

\section{Introduction}

The complexity of long-term sequelae experienced by Holocaust victims has been described in numerous articles worldwide [1-4]. The mental, somatic, and psychosocial development of traumatized Holocaust victims has been assessed for many decades in long-term catamneses $[2,4,5]$. Medical specialists were called in by the Office for Compensation in Germany (Amt für Wiedergutmachung, Trier, Germany) to examine the aspect of compensation by payment to the victims of the Holocaust. The central aim of that office is to assess Holocaustinduced mental and somatic damage and persecutioninduced reduction in earning capacity (verfolgungsbedingte Minderung der Erwerbsfähigkeit, vMdE). The assessment of international reports by German advisory physicians and chief experts finally served to classify the grade of vMdE and/or change the existing classification of individual victims.

The actual focus of judicial applications for compensation of victims is on the deterioration in earning power due to mental, somatic, and psychosocial damage. The primary medical evaluation of the first grade of vMdE was made several decades ago, whereas deterioration of the mental, somatic, and psychosocial situation has been reported by the victims in the meantime. Thus, differ-

\section{KARGER \\ Fax +41613061234 E-Mail karger@karger.ch} www.karger.com

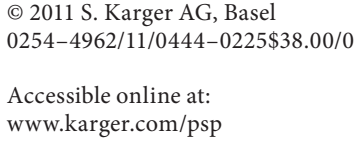

Helge Müller, MD

Department of Psychiatry and Psychotherapy

University of Erlangen-Nuremberg

Schwabachanlage 6, DE-91054 Erlangen (Germany)

Tel. +49 913185 44733, Fax +499131853 4499, E-Mail helge.mueller@uk-erlangen.de 
ences might occur between the consequences of the posttraumatic syndrome directly induced by the Holocaust (HPS) and the posttraumatic stress disorder (PTSD) induced indirectly by the Holocaust at a later stage.

Individual documentation of long-term catamneses between the primary and subsequent expert reports exists of every single case examined. The damage directly caused by the Holocaust as well as the further development of the victims' lives from multidimensional viewpoints (somatic, mental, and psychosocial development after the Holocaust) is documented.

The present study deals with a group of Holocaust survivors who have 'long-term sequelae' due to their Holocaust experience in concentration camps. The study was approved by the Ethics Commission of the University of Erlangen-Nuremberg. The aim of the study was to identify mental and/or somatic damage caused directly by the Holocaust and damage arising in the years after the war in order to improve the classification of an individual subject's vMdE.

Thus it was important to distinguish between (1) primary diagnoses of mental and somatic damage caused directly by the Holocaust and (2) subsequent diagnoses, diseases, and sequelae in the period after the Holocaust.

As a synopsis, the judicially appointed expert was asked to define the interaction between the primary and subsequent diagnoses. Especially the aggravating effect of the later sequelae on the traumatic damage directly induced by the Holocaust was assessed.

From the psychiatric point of view, the extent to which the multidimensional factors caused deterioration had to be ascertained. Deterioration could result from recurrence, increase in intensity of the trauma and/or decrease in coping strategies, which might have impaired the victim's bio-psychosocial abilities to cope with life. An increase in vMdE grade could lead to an increase in payment of the calculated pension.

The following evaluation referred to a multidimensional synopsis of diseases of Holocaust victims on the basis of documented primary and secondary medical reports. It was very difficult to identify interactive variables that induced an aggravation of the psychiatrically relevant vMdE of Holocaust victims.

\section{Methods}

The investigation was based on the evaluation of the complete documents available (medical reports, clinical history, physicians' statements, handwritten declarations made by patients under oath). These reports provided a combination of objective observation and personal, subjective experience. In the present study, only the statements of internationally renowned specialists in the evaluation of Holocaust documents from Israel, North and South America were considered (Office for Compensation, Trier, Germany). The categorization of diagnoses was based on widely used manuals (ICD-9, 10; DSM-III-R; DSM-IV). The diagnostic classification was made by leading specialists on site, based on their own clinical examination. This is common clinical practice in Germany for trauma-related medical reports by psychiatrists. The primary investigation was performed by general practitioners and specialists in internal medicine. When psychiatric abnormalities were found, an additional psychiatric examination was performed by a trauma specialist on site. The final assessment of vMdE was made by a German consulting physician based on the patient's records. The diagnosis was adapted to the German classification system. In case of worsening, a re-examination was performed on site, and the diagnosis was adapted to the latest classification manual (ICD-9, ICD-10, DSM-III, DSM-IV). The vMdE was then assessed by the German consulting physician after review of the complete patient records.

The following categories were applied: (1) Holocaust-induced mental sequelae (main diagnosis and secondary diagnosis); (2) Holocaust-induced somatic sequelae (main diagnosis and secondary diagnosis); (3) Holocaust-independent mental diseases (main diagnosis and secondary diagnosis), and (4) Holocaust-induced somatic diseases (main diagnosis and secondary diagnosis).

The vMdE is based on multivariate factors of somatic and psychiatric sequelae of trauma. A causality of more than $25 \%$ likelihood between traumatization and sequelae was required.

In a first step, assessment of the vMdE grade in sociomedical evaluation was made according to Kisker's criteria. They were measured in $10 \%$ steps. A grade of $50 \%$ or more is present if the person affected shows proximity to psychosis and/or a monofocus on contents of traumata, leading to social isolation combined with massive impairment of social competence. Thus it was necessary to find an adequate cutoff between 0 and $50 \%$. Because a cutoff of $25 \%$ did not fit into the $10 \%$ step system, we chose a cutoff at $30 \%$ in order to be able to dichotomize the selected variable. In this assessment, too, the aspect of synopsis was applied.

In a second step, the evaluation from the aspect of synopsis was carried out on the basis of existing reports. We especially looked at possible interactions of categories 3 and 4 with category 1. A definite evaluation of the aggravation of category 1 symptoms induced by categories 3 and 4 was carried out, if the report by the expert on the spot and the report by an authorized and specialized advisory physician of the Office for Compensation came to the same result. A chief expert was called in if there were discrepancies in the assessment.

\section{Selection of Patients}

The medical reports of 56 (36 female, 20 male) Holocaust victims from Israel, the USA, Canada, and Argentina born between 1911 and 1943 (median: 1926) were evaluated. They were included in this study according to available reports, e.g. for 52 of them (92.3\%) a psychiatric diagnosis was made in the year after liberation, for the remaining 4 (7.7\%) it was made a short time later. All of them had personally met medical experts at their places of residence, appointed by the Office for Compensation, Trier, Germany. The reports were sent to that office after adjustment and eval- 
uated according to German legislation by nationally authorized chief experts (psychiatrists).

\section{Statistical Analysis}

As mentioned above, the grade of vMdE was fixed in $10 \%$ steps. In addition, the variable was dichotomized at a cutoff value of $<30$ vs. $>30 \%$. This dichotomous variable was also applied as dependent variable in a logistic regression model. Differences concerning the number of diagnoses were calculated using nonparametric tests (Kruskal-Wallis test; Mann-Whitney U test). All statistical tests were bilateral. The level of statistical significance was fixed at $\mathrm{p}=0.05$. All calculations were performed with SPSS for Windows 15.0 (SPSS Inc., Chicago, Ill., USA). To exclude malingering, the criteria of Yudorfsky [6] were applied. No signs of malingering were found.

\section{Results}

The evaluation included 56 survivors of the Holocaust (36 women, 20 men), born between 1911 and 1943 (median: 1926). For 52 (92.3\%) of them, a primary psychiatric diagnosis was made in the year after liberation, for the remaining $4(7.7 \%)$ it was made a short time later. Thirtyeight (67.9\%) were married, 15 (26.8\%) were widowed, 2 (3.8\%) were divorced, 1 (1.9\%) was single. Nineteen (50\%) of the married persons were married to a survivor of the Holocaust. Fifty-four (96.4\%) had children, the median number of children was 2 . Sociodemographic factors had no influence on the grade of vMdE in either univariate or multivariate analyses.

As to the number of psychiatric and somatic diagnoses, the latter differed significantly depending on the grade of vMdE (Kruskal-Wallis test: $\chi^{2}=8.5$; d.f. $=3$; $\mathrm{p}=$ 0.037). Above all, the difference in a dichotomized table of vMdE with a cutoff at $30 \%$ was striking (Mann-Whitney $U$ test: $Z=-2.0 ; \mathrm{p}=0.043$ ).

The most frequent diagnoses in our patient population were: (i) psychovegetative exhaustion (65\%), (ii) chronic stress disorder (25\%), and (iii) reactive anxiety neurosis with depressive components (10\%).

The following symptoms (100\%) were found: (i) flashbacks, (ii) reactivation by trigger events, (iii) vegetative symptoms and sleep disturbance, (iv) anxiety, and (v) depression.

Thus, within the (selected) population the diagnostic criteria for PTSD F43.1 were fulfilled. Other diagnoses (e.g. anxiety, depression) were classified as F43.1 if they were related to the trauma. Additional psychiatric diagnoses were F43.21 (24\%), F33 (27\%), F41 (33\%) and F45 (16\%).

Earning Capacity of Holocaust Victims

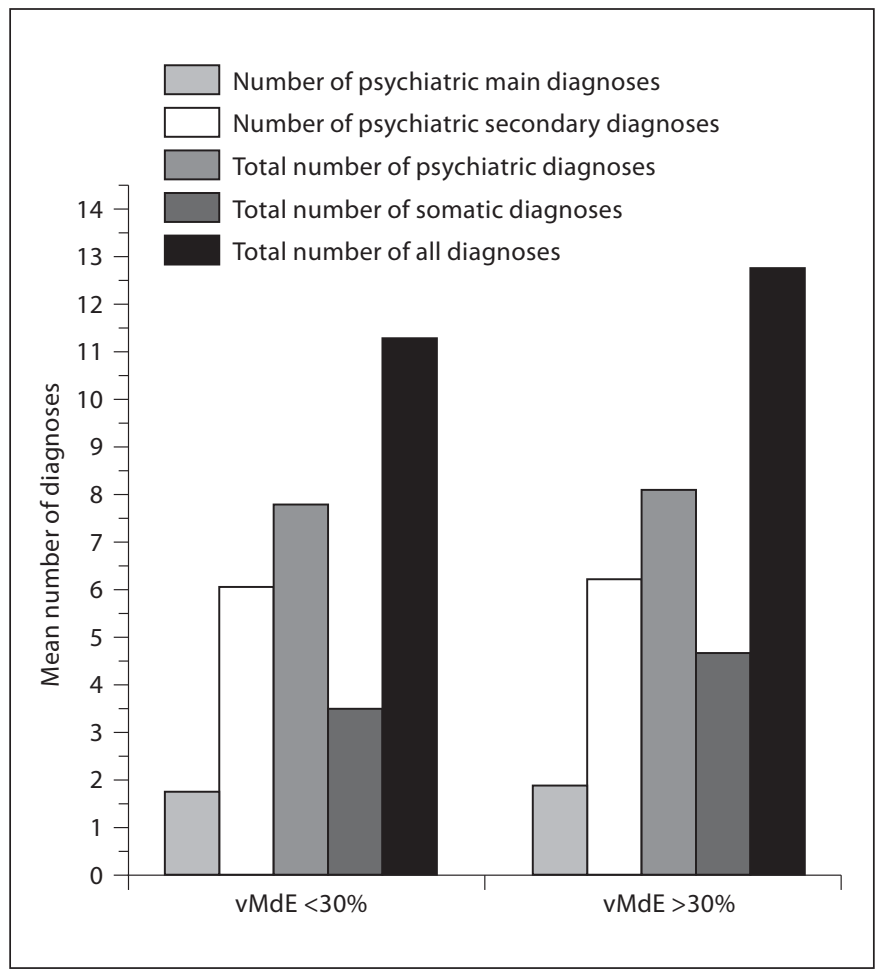

Fig. 1. Diagnoses in relation to the grade of vMdE.

Mean vMdE was $38.5 \pm 8.4 \%$, the mean increase in vMdE during the observation period was $12.8 \pm 6.2 \%$.

It was interesting that the number of psychiatric diagnoses did not matter; even a distinction between main diagnosis and secondary diagnosis did not render significant results. There was no significance even in view of all diagnoses. Figure 1 shows an overall view of the number of diagnoses in relation to the dichotomized vMdE.

The final report on the analysis of vMdE produced similar results. There was, however, a statistical trend of the number of somatic diagnoses (Kruskal-Wallis test: $\chi^{2}=7.2$; d.f. $\left.=3 ; p=0.065\right)$. In a separate analysis of single somatic diseases, a significantly increased number of gastrointestinal complaints was observed in Holocaust survivors graded as $>30 \%$ of $\mathrm{vMdE}\left(\chi^{2}\right.$ test: $\chi^{2}=4.0$; d.f. $=1$; $\mathrm{p}=0.046)$.

Newly acquired mental and somatic diseases correlated with an aggravation of HPS even above the cutoff at $30 \%$ of vMdE up to $40 \%$. Higher grades correlated with newly acquired somatic diseases. Therefore, the cutoff should possibly be changed and a new limitation be set.

Psychopathology 2011;44:225-229 


\section{Discussion}

The concept of the so-called aspect of synopsis in the evaluation of vMdE made great demands on the expert of medical reports about Holocaust victims. The aspect of synopsis failed to show a clear correlation between the increase in HPS and mental and/or somatic diseases in each case.

But on the basis of now available long-term catamnestic evaluation, there were statistically unambiguous trends of an increase in HPS due to somatic and mental influences, which arose in the course of the Holocaust victim's life independent of the Holocaust. These influences were primarily not directly connected with the Holocaust, but they nevertheless induced a remarkable increase in the intensity of HPS in affected victims. Above all, the leading diagnosis of a PTSD showed an aggravation as defined by the criteria of the ICD-10 (F43.10). There was an increase in the complaints 'persistent memories, revival, repeating dreams, symptoms of situations reminding of the burden'.

The increase in HPS induced by somatic diagnosis in the synopsis and therefore higher graded vMdE showed a close correlation with specific old-age illnesses, e.g. disturbances of metabolism, vascular, cardiological, cerebral diseases. Based on the patients examined from the aspect of synopsis in this study, the notable decrease in mental coping strategies in some cases in former Holocaust victims seemed to result more from the decrease in somatic resources than from the influence of additional mental diseases.

A reason for this result could be seen in the somatically induced reduction of the personal radius by less mobility and a resulting reduced level of activity together with a reduction of purpose in life. Several articles have dealt with the phenomenon of the so-called posttrauma or the sequential traumatization of aging in Holocaust victims [7]. The process of getting older was described as an autonomous factor of vulnerability in the sense of a phase after the trauma. Old age comprises an increased probability of mental and somatic weakness which ends up in an exacerbation of traumatic memories. Symptoms that might once have been successfully suppressed then lead to increased anxiety [8]. In the group examined, this phase of posttrauma was confirmed by the dominance of reactivation and recurrence of memories of the traumatic experience.

The decrease in cognitive abilities and memory was examined in studies of Holocaust victims with and without PTSD [9-11]. Persons with PTSD after Holocaust trauma showed a significantly better memory for Holocaust-related word pairs than Holocaust victims without PTSD. The result was just the opposite for neutral, Holocaust-independent word pairs. On the basis of these examinations, the probability of recurrence and reactivation of Holocaust-specific contents in the group of patients with PTSD in old age was confirmed in our study. The decisive point according to our results was a process of somatic aggravation in connection with a decrease in mental resources and coping strategies related to old age.

Finally, it should be discussed whether and to what extent previous traumatization in the sense of PTSD due to Holocaust experience with increased specific vulnerability can also induce vulnerability to somatic comorbidities. These comorbidities are not directly connected with the traumatic events, but they could occur earlier or progress more harshly. Thus, the sequelae could appear as a risk factor for acquiring non-Holocaust-associated diseases.

To control for this suspicion in future studies, a comparison between specifically Holocaust-traumatized patients and a group of otherwise traumatized PTSD patients should be drawn.

\section{Conclusions}

The results of our study lead to the following conclusions:

(1) An increase in HPS caused by mental and/or somatic PTSD after the Holocaust confirmed the assumption that mental complaints of Holocaust victims can be exacerbated after the Holocaust and increase the grade of vMdE.

(2) The central method of the study, the aspect of synopsis, is difficult to apply, but it obviously leads to convincing results. It could possibly be improved by changing the cutoff from 30 to $40 \%$ of vMdE.

(3) New studies should be made in order to find out whether the sequelae experienced by Holocaust victims could be a risk factor for acquiring non-holocaust-associated diseases, which might exacerbate their mental complaints. 


\section{References}

1 Castle DJ, Murray RM: The epidemiology of late-onset schizophrenia. Schizophr Bull 1993;19:691-700.

2 Cohen M, Brom D, Dasberg H: Child survivors of the Holocaust: symptoms and coping after fifty years. Isr J Psychiatry Relat Sci 2001;38:3-12.

3 Miller BL, Benson DF, Cummings JL, Neshkes R: Late-life paraphrenia: an organic delusional syndrome. J Clin Psychiatry 1986; 47:204-207.

4 Reulbach U, Bleich S, Biermann T, Pfahlberg A, Sperling W: Late-onset schizophrenia in child survivors of the Holocaust. J Nerv Ment Dis 2007;195:315-319.
5 Lev-Wiesel R, Amir M: Posttraumatic stress disorder symptoms, psychological distress, personal resources, and quality of life in four groups of Holocaust child survivors. Fam Process 2000;39:445-459.

6 Yudorfsky SC: Malingering; in Kaplan HJ, Sadock QBJ (eds): Comprehensive Textbook of Psychiatry, ed 4. Baltimore, Williams \& Wilkins, 2000, pp 1862-1865.

7 van der Hal-Van Raalte E, Van Ijzendoorn MH, Bakermans-Kranenburg MJ: Quality of care after early childhood trauma and wellbeing in later life: child Holocaust survivors reaching old age. Am J Orthopsychiatry 2007;77:514-522.

8 Ehrlich MA: Health professionals, Jewish religion and community structure in the service of the aging Holocaust survivor. Arch Gerontol Geriatr 2004;38:289-295.
9 Golier JA, Yehuda R, Lupien SJ, Harvey PD: Memory for trauma-related information in Holocaust survivors with PTSD. Psychiatry Res 2003;121:133-143.

10 Golier JA, Yehuda R, Lupien SJ, Harvey PD, Grossman R, Elkin A: Memory performance in Holocaust survivors with posttraumatic stress disorder. Am J Psychiatry 2002;159: 1682-1688.

11 Yehuda R, Tischler L, Golier JA, Grossman R, Brand SR, Kaufman S, Harvey PD: Longitudinal assessment of cognitive performance in Holocaust survivors with and without PTSD. Biol Psychiatry 2006;60:714-721. 